\title{
(อ) OPEN ACCESS \\ Approach to high intracoronary thrombus burden in the era of COVID-19
}

\author{
Kevin M Coy, ${ }^{1}$ Andrii Maryniak, ${ }^{2}$ Thomas Blankespoor, ${ }^{3}$ Adam Stys ${ }^{4}$
}

${ }^{1}$ Cardiology, University of South Dakota, Sioux Falls, South Dakota, USA

${ }^{2}$ SUNY Downstate Medical Center Department of Internal Medicine, Brooklyn, New York, USA

${ }^{3}$ Sanford School of Medicine, University of South Dakota, Sioux Falls, South Dakota, USA ${ }^{4}$ Sanford USD Medical Center Department of CardiologySioux Falls, Sioux Falls, South Dakota, USA

Correspondence to

Dr Kevin M Coy;

coyfishcoyfish@yahoo.com

Accepted 28 October 2021

Check for updates

(c) BMJ Publishing Group Limited 2021. Re-use permitted under CC BY-NC. No commercial re-use. See rights and permissions. Published by BMJ.

To cite: Coy KM, Maryniak A Blankespoor T, et al. BMJ

Case Rep 2021:14:e246223.

doi:10.1136/bcr-2021-

246223

\section{SUMMARY}

Since the start of the COVID-19 pandemic, several cases have reported extensive multivessel coronary thrombosis as a cardiovascular manifestation of SARSCoV-2 infection. This case describes a patient who developed non-ST elevation myocardial infarction during hospitalization for acute hypoxic respiratory failure due to COVID-19. We review the immediate and delayed revascularisation strategies of culprit and non-culprit lesions in the setting of high intracoronary thrombus burden induced by SARS-CoV-2. Successful percutaneous intervention and stenting of a culprit lesion and resolution of an intracoronary thrombus using a delayed strategy of lesion passivation with adjuvant pharmacotherapy are demonstrated on index and followup angiography.

\section{BACKGROUND}

COVID-19-associated coagulopathy has accentuated the large intracoronary thrombus (ICT) burden that is often seen among patients undergoing angiography for acute coronary syndromes (ACS). Through mechanisms that are poorly understood, the virus induces a prothrombotic milieu that leads to the emergence of post infectious microvascular and macrovascular thrombi. ${ }^{1-4}$ Treatment of patients with coincident diagnoses of ACS and COVID-19 is challenging because of uncertain disease pathophysiology. Selection of an appropriate revascularisation strategy depends on the grade of thrombus burden, degree of intracoronary occlusion, preservation of distal flow, duration of thrombus presence, anatomical considerations and clinical status. Low thrombus burden can be approached with manual aspiration or thrombectomy which obviates the need for further angioplasty or stenting. Thrombus removal or dissolution by such means may not be sufficient when high thrombus burden is present. In these cases, percutaneous coronary intervention (PCI) or lesion passivation with adjuvant pharmacotherapy followed by delayed coronary stenting may be necessary to re-establish anterograde flow.

\section{CASE PRESENTATION}

A 64-year-old man with chronic lymphocytic leukaemia, chronic obstructive pulmonary disease, smoking history and hyperlipidaemia, was initially treated for mild-to-moderate COVID-19 with bamlanivimab and discharged home. COVID-19 was diagnosed by nasopharyngeal swab RT-PCR testing. Due to progressive dyspnoea, he returned to the hospital and was admitted for hypoxic respiratory failure further complicated by diffuse interstitial fibrosis and acute respiratory distress syndrome. He required therapy with convalescent plasma, dexamethasone, remdesivir, supplemental oxygen and broad-spectrum antibiotics. Later into his hospitalisation, the patient developed acute onset chest pain with ECG showing minimal inferior ST segment elevations. He characterised his chest pain as a non-exertional, substernal pressure, accompanied by radiation to upper extremities, that subsided spontaneously after $30 \mathrm{~min}$. Relevant cardiac history included a nuclear stress test 1 year prior to presentation that did not identify any fixed or reversible perfusion defects. The patient was transferred to our tertiary care facility for further evaluation of ACS. Intake vitals were unremarkable and physical examination was notable only for trace bibasilar crackles. Repeat ECG showed resolution of prior nonspecific ST segment changes with persistence of a $\mathrm{T}$ wave inversion in V3 (figure 1).

\section{INVESTIGATIONS}

Cardiac and procoagulant biomarkers were elevated. High sensitivity troponin I reached a peak value of $3.367 \mathrm{ng} / \mathrm{dL}$, D-dimer level was measured at $1.07 \mu \mathrm{g} / \mathrm{mL}$, prothrombin time was $14.9 \mathrm{~s}$, activated partial thromboplastin time was $36 \mathrm{~s}$ and international normalised ratio was 1.2. Transthoracic echocardiography revealed a preserved left ventricular ejection fraction of $56 \%$ without evidence of diastolic dysfunction. The patient was diagnosed with non-ST segment elevation myocardial infarction and was treated with loading and maintenance doses of oral aspirin and intravenous unfractionated heparin in anticipation of coronary angiography. Left heart catheterisation identified right dominant circulation, and severe multivessel disease comprising $70 \%$ stenosis of the mid LAD, $80 \%$ stenosis of the distal LAD and $70 \%$ stenosis of the RCA with high-grade thrombus burden.

\section{TREATMENT}

Successful Fractional Flow Reserve-guided angioplasty and drug-eluting stenting of the mid and distal left anterior descending artery was performed with postintervention TIMI 3 flow (figure 2). In lieu of coronary angioplasty, the right coronary artery thrombus measuring $8 \mathrm{~mm} \times 3.6 \mathrm{~mm}$ was treated pharmacologically with oral aspirin, ticagrelor and apixaban with plans to repeat angiography in 4-6 weeks.

\section{OUTCOME AND FOLLOW-UP}

Follow-up angiography 6 weeks later revealed nonobstructive RCA disease with complete resolution 


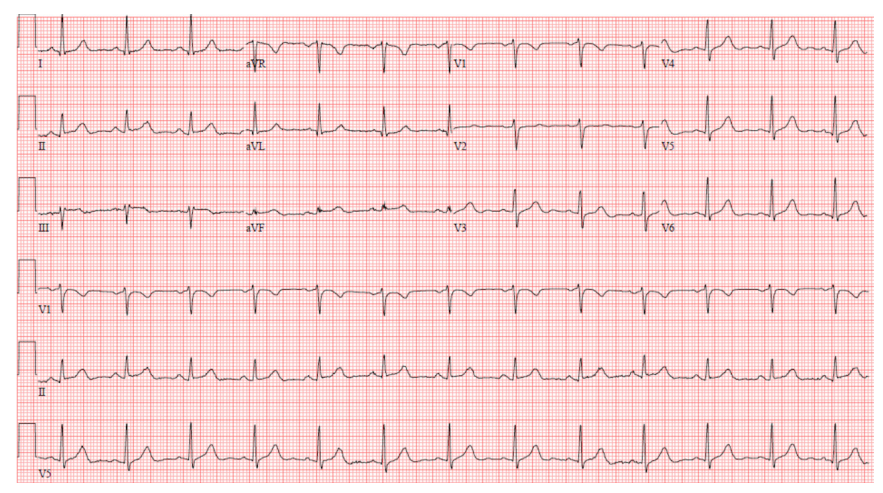

Figure 1 ECG on initial presentation revealing normal sinus rythm with subtle ST elevations in leads II, III and aVF.

of thrombus with anticoagulation (figure 3). The mid RCA was $40 \%$ stenosed and optical coherence tomography revealed a cross-sectional area of $4.5 \mathrm{~mm}^{2}$ with mild aneurysmal dilation and no calcium or thrombus present. Aspirin was discontinued and the patient was instructed to continue dual therapy with ticagrelor and apixaban for at least 1 more month at which time replacement of apixaban with aspirin would be deliberated.

\section{DISCUSSION}

Clinical practice guidelines for management of non-ST-segment acute coronary syndromes (NSTE-ACS) advocate for treatment with PCI. ${ }^{5}$ An immediate invasive strategy ( $<2$ hours) is recommended for very high risk patients such as those with haemodynamic instability or life-threatening arrhythmias, whereas less acute patients should undergo a selective invasive ( $<72$ hours) approach with initial deferral of PCI. A delayed strategy may be augmented with adjuvant antiplatelet therapy and anticoagulation which serves to reduce thrombus evolution prior to index angiography. ${ }^{5}$ Special consideration must be given to patients in whom index angiography reveals a high-grade thrombus burden in the infarct-related artery or non-culprit vessels. ${ }^{6}$ Such patients are at an increased risk of distal embolisation with interventional revascularisation. There is also concern for microvascular obstruction, periprocedural complications and no-reflow/ slow-flow phenomenon. ${ }^{6}$ These adverse outcomes can be attenuated with preventative strategies such as pharmacological pretreatment, percutaneous catheter aspiration, thrombectomy, embolic protection devices, ultrasound enhanced thrombolysis or deferred coronary stenting. ${ }^{8-11}$

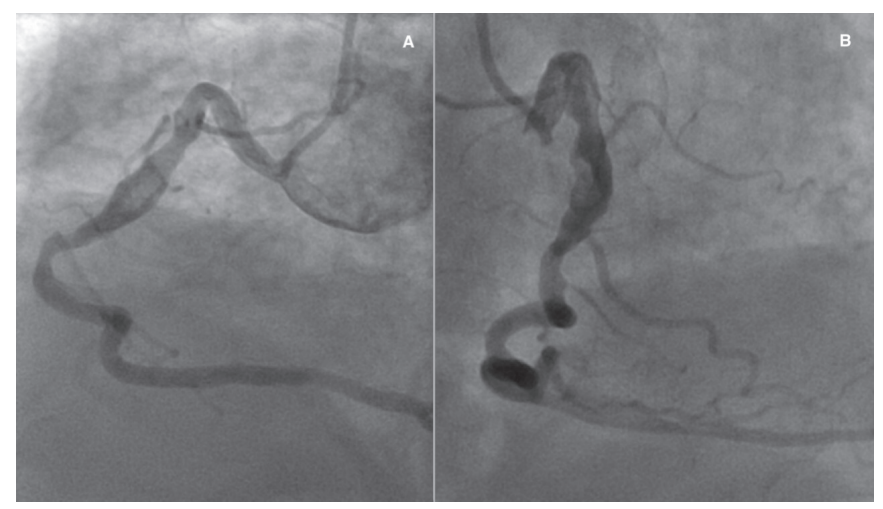

Figure 2 Index angiography of the right coronary artery revealing a large mid thrombus on left anterior oblique $(A)$ and right anterior oblique cranial (B) views.

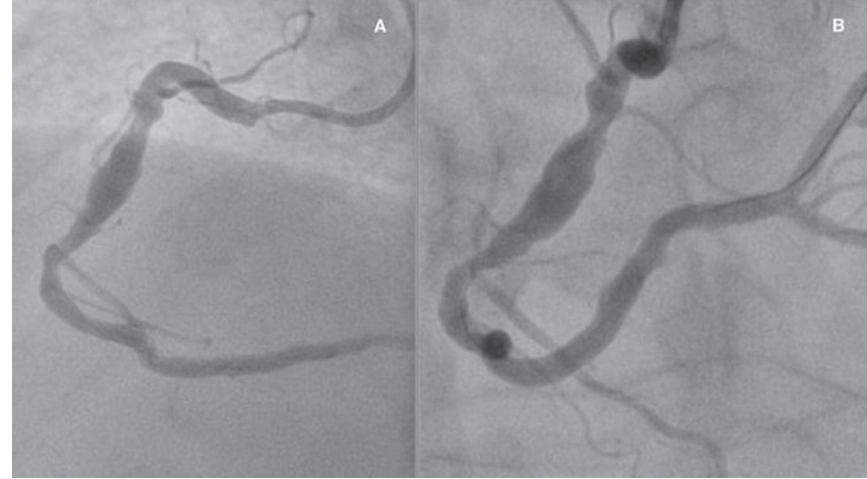

Figure 3 Repeat angipgraphy after 6 weeks of aspirin, ticagrelor and apixaban revealing complete resolution of the thrombus on left anterior oblique (A) and posterior anterior cranial (B) views.

Selection of appropriate management relies on a review of multiple factors. The timing of PCI is heavily influenced by a graded assessment of thrombus burden, coronary anatomy and duration of thrombus presence. Longstanding thrombus can be refractory to instrumentation because of strong intimal adherence stemming from different variants of fibrin deposition at the time of thrombogenesis. ${ }^{10} 12$ This may necessitate pharmacological thrombus dissolution prior to attempted device-mediated extraction. The TIMI thrombus grading system was formulated in order to evaluate thrombus burden based on visual angiographic assessment and can help guide management decisions before and during intervention. ${ }^{10-12}$ High thrombus burden may often preclude immediate revascularisation due to the aforementioned complications and an interim period of adjunctive antiplatelet/antithrombotic therapy with deferred stenting may offer more favourable outcomes. ${ }^{9} 101314$

In our patient, angiography revealed severe multivessel disease and the mid and distal LAD was treated with FFR guided angioplasty and drug-eluting stenting. The therapeutic rationale for deferred angioplasty of the RCA lesion was the presence of TIMI grade 4 thrombus burden and preserved TIMI 3 distal flow, in the context of the prothrombotic milieu that has been associated with SARS-CoV-2 infection. ${ }^{12} 1516$ The most important underlying risk factor for formation of such thrombus is the hypercoagulable state induced by SARS-CoV-2 infection. Given the diagnosis of COVID-19 1 month prior to NSTE-ACS, it was presumed that the ICT had been present for several weeks and was likely well evolved. The pathophysiology underlying the hypercoagulable state in COVID-19 is poorly understood; however, it is believed that a severe inflammatory response triggers a dysfunctional cascade of inflammatory thrombosis that initially occurs in the pulmonary vasculature. ${ }^{15} 16$ In some cases, this is followed by a generalised coagulopathy that involves the epicardial and subepicardial vessels leading to extensive coronary thrombosis. ${ }^{1-4}$ There have been reports of an increased prevalence of ACS in patients with COVID-19 as well as increased mortality from cardiovascular causes that may be related to high grade ICT burden. ${ }^{17-19}$ Despite inconclusive evidence for the efficacy of anticoagulation in COVID-19-associated coagulopathy, ${ }^{1-41516}$ our patient was successfully treated with apixaban in addition to dual antiplatelet therapy.

Most studies on deferred PCI in the setting of high thrombus burden have focused on patients with ST elevation myocardial infarction (STEMI); however, similar principles apply to all patients with ACS. To date, randomised controlled trials (RCTs) have yet to provide definitive evidence for any benefit of 
deferred PCI in patients with STEMI with respect to hard clinical endpoints. ${ }^{8} 131418$ Select patients with preserved TIMI 2-3 flow, high thrombus burden, long lesion length $(>24 \mathrm{~mm})$ and high risk features for slow flow, are most likely to benefit from a procrastinated approach. ${ }^{813}$ The optimal time of deferment is another equivocal issue. In most published RCTs, the usual time elapsed since index angiography is $24-72$ hours, but some studies have postponed secondary PCI for up to 30 days. ${ }^{8}{ }^{83}$

\section{Learning points}

- Multivessel coronary thrombosis triggered by a severe inflammatory response is a significant cardiovascular manifestation of COVID-19.

- Selecting an appropriate revascularisation strategy in the setting of high intracoronary thrombus burden requires weighing the advantages and pitfalls of deferred percutaneous coronary intervention compared with immediate revascularisation.

- Advantages of deferral include thrombus dissolution, enhanced microvascular flow, reduction of vasospasm facilitating better stent sizing, prevention of distal embolisation, avoidance of no-reflow, improved myocardial salvage and possibly negating the need for subsequent stenting.

- The pitfalls of deferral may include prolonged hospitalisation, increased financial burden, the need to undergo two procedures, reocclusion and increased bleeding risk from prolonged anticoagulation.

- Select patients with preserved TIMI 2-3 flow, high thrombus burden, long lesion length ( $>24 \mathrm{~mm})$, and high risk features for slow flow, are most likely to benefit from a procrastinated approach.

Contributors KMC: first author who directly provided patient care and provided oversight as well as writing of this case report. AM: second author who performed literature review and assisted in writing. TB: medical student who assisted with chart review, data collection and formatting. AS: cardiology attending physician who cared for the patient and provided oversight for all aspects of this case report.

Funding The authors have not declared a specific grant for this research from any funding agency in the public, commercial or not-for-profit sectors.

Competing interests None declared.

Patient consent for publication Consent obtained directly from patient(s) Provenance and peer review Not commissioned; externally peer reviewed.

Open access This is an open access article distributed in accordance with the Creative Commons Attribution Non Commercial (CC BY-NC 4.0) license, which permits others to distribute, remix, adapt, build upon this work non-commercially, and license their derivative works on different terms, provided the original work is properly cited and the use is non-commercial. See: http://creativecommons.org/ licenses/by-nc/4.0/.

Case reports provide a valuable learning resource for the scientific community and can indicate areas of interest for future research. They should not be used in isolation to guide treatment choices or public health policy.

\section{REFERENCES}

1 Kermani-Alghoraishi M. A review of coronary artery thrombosis: a new challenging finding in COVID-19 patients and ST-elevation myocardial infarction. Curr Probl Cardiol 2021;46:100744.

2 Pellegrini D, Kawakami R, Guagliumi G, et al. Microthrombi as a major cause of cardiac injury in COVID-19: a pathologic study. Circulation 2021;143:1031-42.

3 Tedeschi D, Rizzi A, Biscaglia S, et al. Acute myocardial infarction and large coronary thrombosis in a patient with COVID-19. Catheter Cardiovasc Interv 2021;97:272-7.

4 Dominguez-Erquicia P, Dobarro D, Raposeiras-Roubín S, et al. Multivessel coronary thrombosis in a patient with COVID-19 pneumonia. Eur Heart J 2020;41:2132.

5 Collet J-P, Thiele H, Barbato E, et al. 2020 ESC guidelines for the management of acute coronary syndromes in patients presenting without persistent ST-segment elevation. Eur Heart J 2021;42:1289-367.

6 Banning AS, Gershlick AH. Timing of intervention in non-ST segment elevation myocardial infarction. European Heart Journal Supplements 2018;20:B10-20.

7 Rezkalla SH, Kloner RA. No-reflow phenomenon. Circulation 2002;105:656-62.

8 Pradhan A, Bhandari M, Vishwakarma P, et al. Deferred stenting for heavy thrombus burden during percutaneous coronary intervention for ST-elevation MI. Eur Cardiol 2021;16:e08.

9 Sharma J. Facing the intracoronary thrombus burden: the two-step approach to coronary stenting. Cath lab digest, 2013. Available: https://www.cathlabdigest. com/articles/Facing-Intracoronary-Thrombus-Burden-Two-Step-Approach-CoronaryStenting [Accessed 24 Apr 2021].

10 Sathananthan J, PJL 0, Khoo D. Management of Intracoronary Thrombus. In: Watson TJ, PJL O, Theng JE, eds. Primary angioplasty. Singapore: Springer, 2018: 345-96.

11 Choudry FA, Weerackody RP, Jones DA, et al. Thrombus embolisation: prevention is better than cure. Interv Cardio/ 2019;14:95-101.

12 Adnan G, Singh DP, Mahajan K. Coronary Artery Thrombus. In: StatPearls. Treasure Island (FL): StatPearls Publishing, 2020.

13 De Maria GL, Alkhalil M, Oikonomou EK, et al. Role of deferred stenting in patients with ST elevation myocardial infarction treated with primary percutaneous coronary intervention: a systematic review and meta-analysis. J Interv Cardiol 2017;30:264-73.

14 Carrick D, Oldroyd KG, McEntegart M, et al. A randomized trial of deferred stenting versus immediate stenting to prevent no- or slow-reflow in acute ST-segment elevation myocardial infarction (DEFER-STEMI). J Am Coll Cardiol 2014;63:2088-98.

15 Abou-Ismail MY, Diamond A, Kapoor S, et al. The hypercoagulable state in COVID-19: incidence, pathophysiology, and management. Thromb Res 2020;194:101-15.

16 Connors JM, Levy JH. Thromboinflammation and the hypercoagulability of COVID-19. J Thromb Haemost 2020;18:1559-61.

17 Choudry FA, Hamshere SM, Rathod KS, et al. High Thrombus Burden in Patients With COVID-19 Presenting With ST-Segment Elevation Myocardial Infarction. J Am Coll Cardiol 2020;76:1168-76

18 Pandit BN, Shrivastava A, Nath RK, et al. Impact of COVID-19 on thrombus burden and outcome in acute myocardial infarction. Cureus 2021;13:e16817.

19 Bonow RO, Fonarow GC, O'Gara PT, et al. Association of coronavirus disease 2019 (COVID-19) with myocardial injury and mortality. JAMA Cardiol 2020;5:751-3.

Copyright 2021 BMJ Publishing Group. All rights reserved. For permission to reuse any of this content visit

https://www.bmj.com/company/products-services/rights-and-licensing/permissions/

BMJ Case Report Fellows may re-use this article for personal use and teaching without any further permission.

Become a Fellow of BMJ Case Reports today and you can:

- Submit as many cases as you like

- Enjoy fast sympathetic peer review and rapid publication of accepted articles

- Access all the published articles

- Re-use any of the published material for personal use and teaching without further permission

Customer Service

If you have any further queries about your subscription, please contact our customer services team on +44 (0) 2071111105 or via email at support@bmj.com.

Visit casereports.bmj.com for more articles like this and to become a Fellow 